\title{
Multiloop interleaved control for three-level buck converter in solar charging applications
}

\author{
Zhi Zhang ${ }^{1 \mathrm{a})}$, Hao Zhou ${ }^{1}$, Chengliang Deng ${ }^{1}$, and Qinghua Song ${ }^{2}$ \\ ${ }^{1}$ School of Electronic Engineering, Dongguan University of Technology, \\ Dongguan 523808, China \\ ${ }^{2}$ East Group Co., Ltd., Dongguan 523808, China \\ a) zhangz@dgut.edu.cn
}

\begin{abstract}
In this paper, a nonisolated three-level (TL) buck converter is used for high voltage high power solar charging application. In order to search the maximum power point tracking (MPPT) point, keep the capacitor voltage balance and realize the function of constant current (CC) and constant voltage (CV) charging, a multiloop interleaved control (MIC) method is proposed. The proposed TL buck battery charger and the MIC method have the advantage of lower inductor current ripple, lower switch withstanding voltage and lower switching loss compared with the conventional buck charger. The proposed MIC method is digitally implemented by a digital-signal-processor (DSP)-based system. Simulation and experimental results based on a $4000 \mathrm{~W}$ prototype circuit are presented to demonstrate the effectiveness of the proposed control method.
\end{abstract}

Keywords: three-level buck converter, solar, voltage balance Classification: Power devices and circuits

\section{References}

[1] H. C. Chen and W. J. Lin: "MPPT and voltage balancing control with sensing only inductor current for photovoltaic-fed, three-level, boost-type converters," IEEE Trans. Power Electron. 29 (2014) 29 (DOI: 10.1109/TPEL.2013. 2262056).

[2] Y.-C. Chuang and Y.-L. Ke: "High-efficiency and low-stress ZVT-PWM DCto-DC converter for battery charger," IEEE Trans. Ind. Electron. 55 (2008) 3030 (DOI: 10.1109/TIE.2008.921218).

[3] H. Haga and F. Kurokawa: "Modulation method of a full-bridge three-level LLC resonant converter for battery charger of electrical vehicles," IEEE Trans. Power Electron. 32 (2017) 2498 (DOI: 10.1109/TPEL.2016.2570800).

[4] Y.-C. Chuang: "High-efficiency ZVS buck converter for rechargeable batteries," IEEE Trans. Ind. Electron. 57 (2010) 2463 (DOI: 10.1109/TIE. 2009.2035459).

[5] S. Pattnaik, et al.: "Efficiency improvement of synchronous buck converter by passive auxiliary circuit," IEEE Trans. Ind. Electron. 46 (2010) 2511 (DOI: 10.1109/TIA.2010.2070831).

[6] X. Long, et al:: "Low-cost charge collector of photovoltaic power conditioning system based dynamic DC/DC topology," IET Renew. Power Gener. 5 (2011) 167 (DOI: 10.1049/iet-rpg.2009.0199). 
[7] A. Farooq, et al.: "An integrated inverted and non-inverted buck converter," IEICE Electron. Express 13 (2016) 20151082 (DOI: 10.1587/elex.13. 20151082).

[8] A. S. Werulkar and P. S. Kulkarni: "Design of a constant current solar charge controller with microcontroller based soft switching buck converter for solar home lighting system," IEEE PEDES (2012) 1 (DOI: 10.1109/PEDES.2012. 6484337).

[9] Z. Zhang, et al.: "A single stage soft-switched AC/DC power factor corrected converter with galvanic isolation," IEICE Electron. Express 14 (2017) 20170144 (DOI: 10.1587/elex.14.20170144).

[10] X. Ruan, et al.: "There-level converters - a new approach for high voltage and high power DC-to-DC conversion,” IEEE PESC (2002) 663 (DOI: 10.1109/ PSEC.2002.1022529).

\section{Introduction}

The photovoltaic power generation system is built worldwide in private and commercial applications recently, and the stand-alone PV system is attractive for supplying the required electricity in remote areas. Solar battery charger is the crucial component of the stand-alone PV system [1]. It can adjust the PV panel output power in order to find the maximum power operating points, and it also prevents batteries from excessive overcharge.

Several DC-DC converters proposed in $[2,3,4,5,6,7,8]$ are used to design the battery charger. They are divided into isolated [3] and nonisolated topologies. Isolated converters such as flyback or isolated cuk [9] converter are suitable for high conversion ratio applications, however these topologies have the problems of low conversion efficiency, high voltage stress, high switching losses and significant electromagnetic interference. Nonisolated DC-DC topologies [2, 3, 4, 7] have the advantage of simple structure, and they are suitable for improving conversion efficiency and reducing the cost of the system. A dynamic buck/boost topology with micro-controller is designed to meet the low-cost application [6]. In [2], a highly efficient ZVT-PWM soft-switching buck converter is proposed for battery charger. The ZCS buck converter and synchronous buck converter also provide high efficient solution for battery charge applications in [4]. However, these topologies and control methods are only suitable for low power application.

In high voltage and high power application, the multilevel DC-DC converter is more attractive, because it has the advantage of the reduction of switches voltage stress, the significantly reduced filter $[1,10]$.

In this paper, the three-level (TL) buck converter is used for high voltage high power battery charger application, and the MIC method is proposed which is combined with multiloop control and the interleaved pulse width modulation scheme. Lower voltage stress, current ripple and switching loss could be achieved compared with the conventional buck charger. The proposed control method is digitally implemented and verified in a DSP-based system. 


\section{Circuit converter and operating principle}

The conventional two-level buck and the proposed three-level buck-type battery charger are shown in Fig. 1(a) and Fig. 1(a) separately. The proposed three-level buck-type converter consists of two power switching devices of $\mathrm{Q}_{1}$ and $\mathrm{Q}_{2}$, one inductor $\mathrm{L}$, two diodes of $\mathrm{D}_{1}$ and $\mathrm{D}_{2}$, two capacitors of $\mathrm{C}_{1}$ and $\mathrm{C}_{2}$ in the input side and one capacitor $\mathrm{C}_{\text {out }}$ in output side. Assuming that the capacitor voltage $\mathrm{U}_{\mathrm{c} 1}=\mathrm{U}_{\mathrm{c} 2}$, so when the power device of $\mathrm{Q}_{1}$ or $\mathrm{Q}_{2}$ is turned off, the voltage stress is only half of the $U_{P V}$.

There are four possible switching states when the converter can operate, depending on the duty ratio $\mathrm{D}$ of switches $\mathrm{Q}_{1}$ and $\mathrm{Q}_{2}$. As the interleaved control method is proposed in this paper, there is a phase difference of $180^{\circ}$ between two driver signals for $\mathrm{Q}_{1}$ and $\mathrm{Q}_{2}$.

The following assumptions are made for the system analysis:

(1) All the components are ideal;

(2) Two capacitors of $\mathrm{C}_{1}$ and $\mathrm{C}_{2}$ are large enough, and the voltage of two capacitors satisfies $\mathrm{U}_{\mathrm{c} 1}=\mathrm{U}_{\mathrm{c} 2}=0.5 \mathrm{U}_{\mathrm{PV}}$.

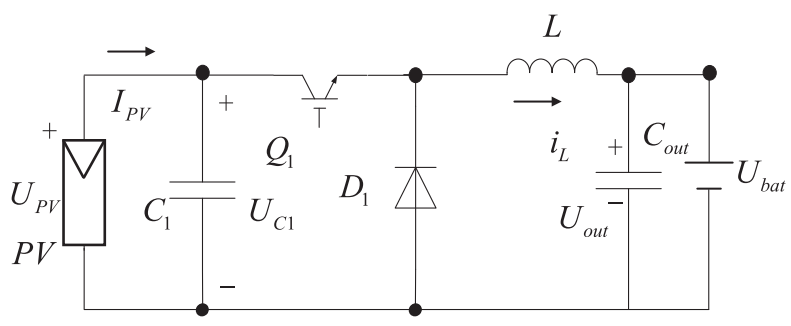

(a) conventional buck charger

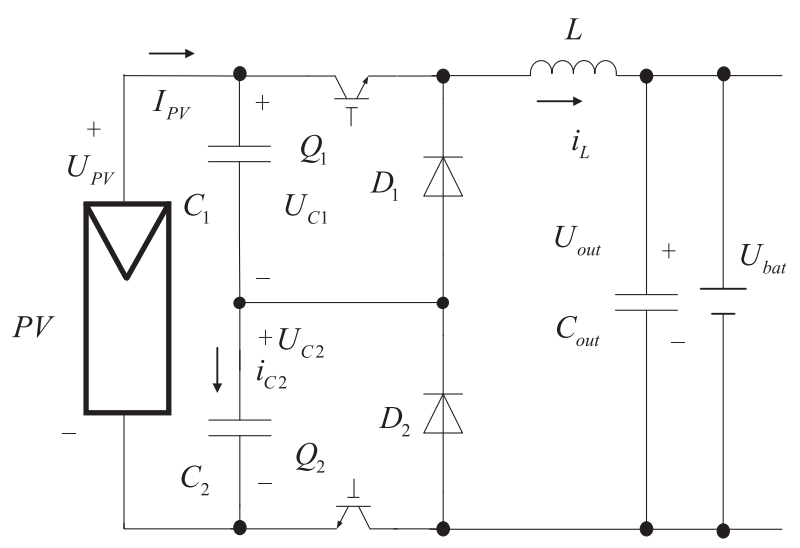

(b) proposed three-level buck charger

Fig. 1. Three-level buck converter for battery charger

\subsection{Situation for $D>0.5$}

The operation waveforms are shown in Fig. 3(a), both duty ration D of switches $\mathrm{Q}_{1}$ and $\mathrm{Q}_{2}$ are larger than 0.5 .

At time $\mathrm{t}_{0}$, the switches $\mathrm{Q}_{1}$ and $\mathrm{Q}_{2}$ turn on as shown in Fig. 2(a), the inductor $\mathrm{L}$ is being linearly charged, and the inductor current is given in Eq. (1)

$$
i_{L(t)}=i_{L(t 0)}+\frac{U_{P V}-U_{0}}{L}\left(t-t_{0}\right)
$$




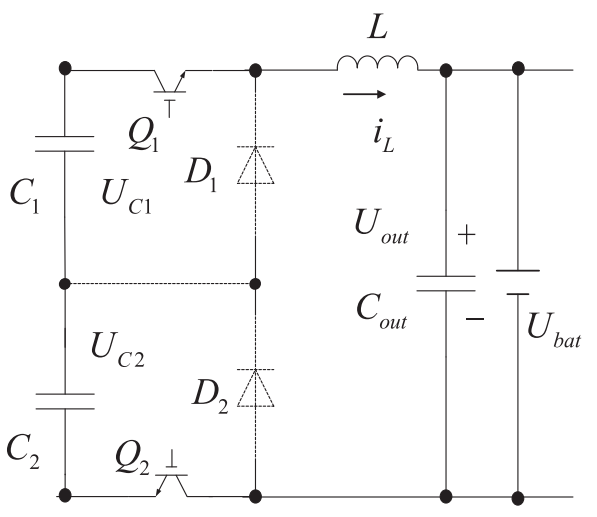

(a) state 1

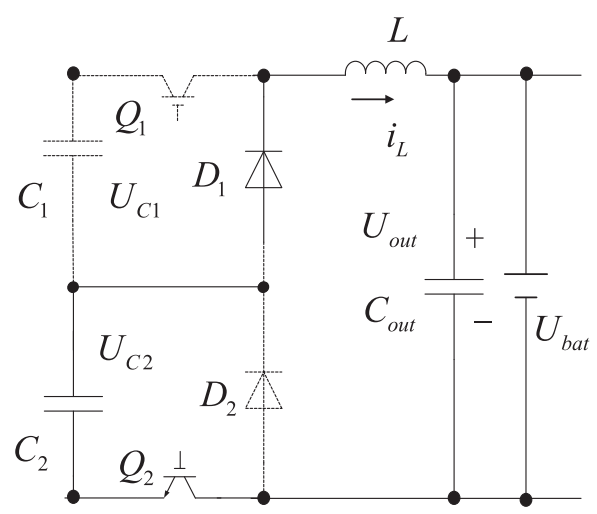

(c) state 3

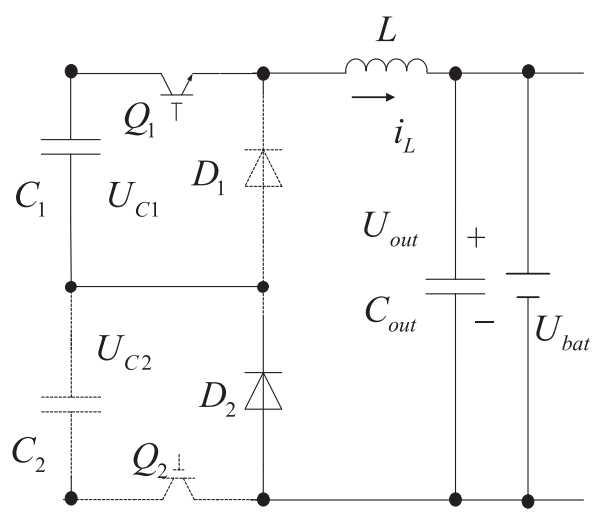

(b) state 2

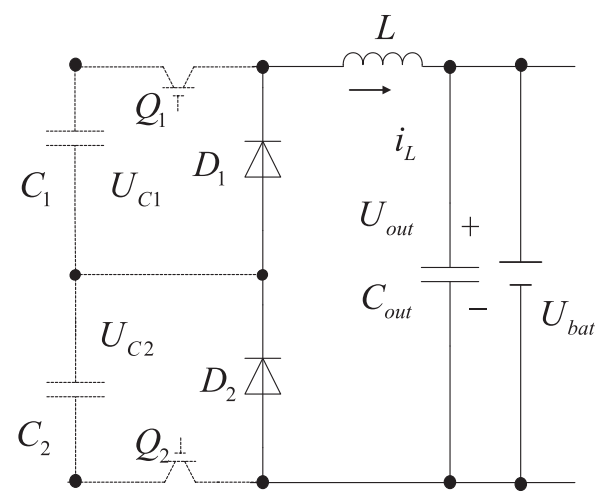

(d) state 4

Fig. 2. Operation modes of three-level buck converter

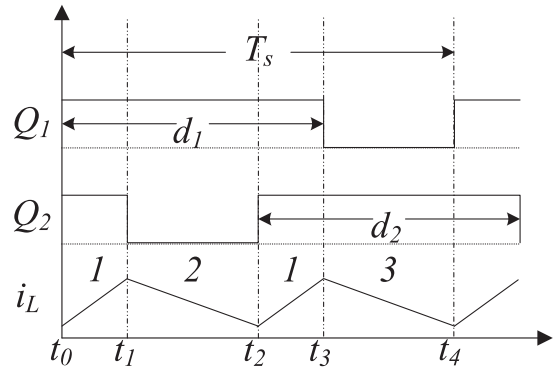

(a) $d>0.5$

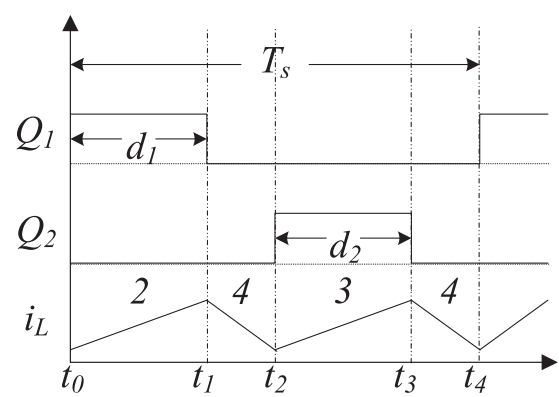

(b) $\mathrm{d}<0.5$

Fig. 3. Key waveforms of the three-level buck converter

At time $t_{1}$, the switch $Q_{2}$ turns off as shown in Fig. 2(b), and the inductor current flows through diode $\mathrm{D}_{2}$ to input capacitor $\mathrm{C}_{1}$. As the inductor current $\mathrm{i}_{\mathrm{L}}>0$, the bottom capacitor $\mathrm{C}_{2}$ is charged and the top capacitor $\mathrm{C}_{1}$ is discharged. The inductor $\mathrm{L}$ is discharged until time $\mathrm{t}=\mathrm{t}_{2}$, the inductor current is given in Eq. (2)

$$
i_{L(t)}=i_{L(t 1)}+\frac{U_{P V} / 2-U_{0}}{L}\left(t-t_{1}\right)
$$

At time $t_{2}$, the switch $Q_{2}$ turns on, and the inductor current is charged with the input voltage again.

At time $t_{3}, Q_{1}$ turns off as shown in Fig. 2(c), the inductor current $i_{L}=-i_{C 2}$, thus, the capacitor $C_{2}$ is discharged, and the other capacitor $C_{1}$ is charged, the 
inductor current will go through $\mathrm{Q}_{2}, \mathrm{C}_{2}$ and $\mathrm{D}_{1}$, and it is discharged by $U_{P V} / 2-U_{0}$ again.

\subsection{Situation for $D<0.5$}

The operation waveforms are shown in Fig. 3(b).

At time $t_{0}, Q_{1}$ turns on and $\mathrm{Q}_{2}$ turns off as shown in Fig. 2(b), the inductor current flows through $\mathrm{C}_{\text {out }}, \mathrm{D}_{2}, \mathrm{C}_{1}, \mathrm{Q}_{1}$, and the inductor $\mathrm{L}$ is being linearly charged, it is given in Eq. (3)

$$
i_{L(t)}=i_{L(t 0)}+\frac{U_{P V} / 2-U_{0}}{L}\left(t-t_{0}\right)
$$

At time $t_{1}$, both switches turn off as shown in Fig. 2(d), the inductor voltage is equal to the battery voltage. The inductor $L$ is discharged until time $t=t_{2}$, and the inductor current is given in Eq. (4)

$$
i_{L(t)}=i_{L\left(t_{1}\right)}-\frac{U_{0}}{L}\left(t-t_{1}\right)
$$

At time $t_{2}$, the switch $\mathrm{Q}_{2}$ turns on and the switch $\mathrm{Q}_{1}$ turns off as shown in Fig. 2(c), the inductor current is charged until $t=t_{3}$. The bottom capacitor $C_{2}$ is discharged, and the top capacitor $\mathrm{C}_{1}$ is charged again.

At time $t_{3}, Q_{2}$ turns off as shown in Fig. 2(d), the inductor $L$ is discharged again.

\section{Proposed control method}

The proposed control method for the three-level buck is shown in Fig. 4. By sampling PV voltage $\mathrm{U}_{\mathrm{pv}}$ and current $\mathrm{I}_{\mathrm{PV}}$, it is convenient to find the maximum

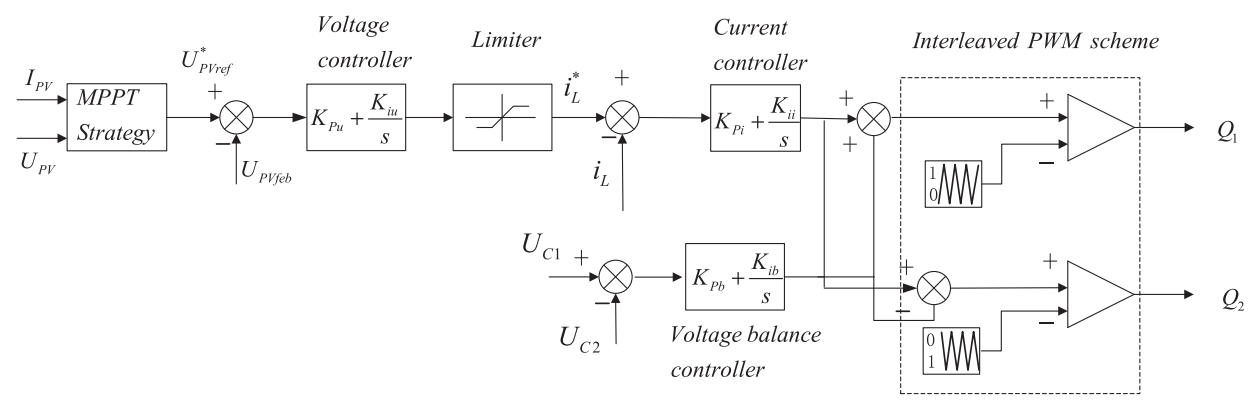

(a) Constant current Charging

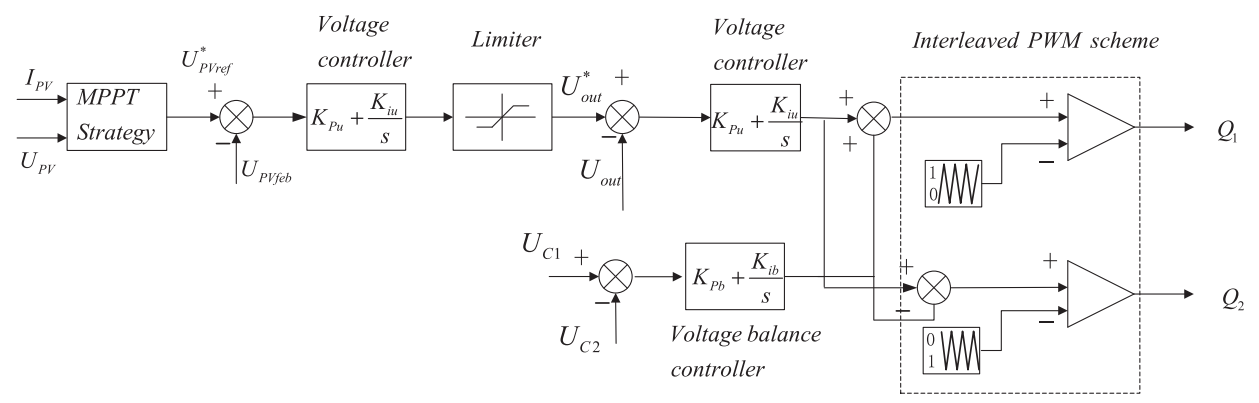

(b) Constant voltage Charging

Fig. 4. Proposed multiloop and interleaved control method for threelevel buck converter 
power point. The proposed controller combines the multiloop control and the interleaved PWM scheme. Both the voltage and current controller are proportional-integral-type controllers. The proposed method is able to yield smaller inductor current ripple and lower voltage stress of the switches.

The three-level buck converter has two cascaded capacitors, and each power switch needs to withstand only a half of input voltage, so the additional voltage balance control loop is required to balance both capacitor voltage. If the capacitor voltage $U_{c 1}$ is higher than the capacitor $U_{c 2}$, the conducting time of switch $Q_{1}$ should be increased, and the conducting time of switch $\mathrm{Q}_{2}$ should be decreased. If the capacitor voltage $U_{c 2}$ is higher than the capacitor voltage $U_{c 1}$, the situation is similar.

\section{Experimental result}

Table I. System parameters of three-level buck converter

\begin{tabular}{c|c|c|c}
\hline $\mathrm{U}_{\text {bat }}$ voltage & $360 \mathrm{~V}$ & Switch frequency & $20 \mathrm{kHz}$ \\
\hline Inductor $\mathrm{L}_{1}$ & $0.5 \mathrm{mH}$ & IGBT switch & SGL50N60RUFD \\
\hline Capacitance $\mathrm{C}_{1}, \mathrm{C}_{2}$ & $3400 \mathrm{uF}$ & Capacitance $\mathrm{C}_{\text {out }}$ & $1200 \mathrm{uF}$ \\
\hline
\end{tabular}

Table II. System parameters of PV panels

\begin{tabular}{c|c}
\hline Rated power & $265 \mathrm{~W}$ \\
\hline Voltage at maximum power & $30.5 \mathrm{~V}$ \\
\hline Current at maximum power & $8.7 \mathrm{~A}$ \\
\hline Open circuit voltage & $37.8 \mathrm{~V}$ \\
\hline Short-circuit current & $9.18 \mathrm{~A}$ \\
\hline
\end{tabular}

A $4000 \mathrm{~W}$ experimental prototype of the solar battery charger has been built and tested to verify the effectiveness of the proposed MIC method based on a DSPbased system with the TMS320F28035 chip.

The system parameters of TL buck converter and PV panels are summarized in Table I and II. 16 PV panels are connected in series, and the proposed charging circuit is applied to a $360 \mathrm{~V}, 100 \mathrm{Ah}$ lead-acid battery.

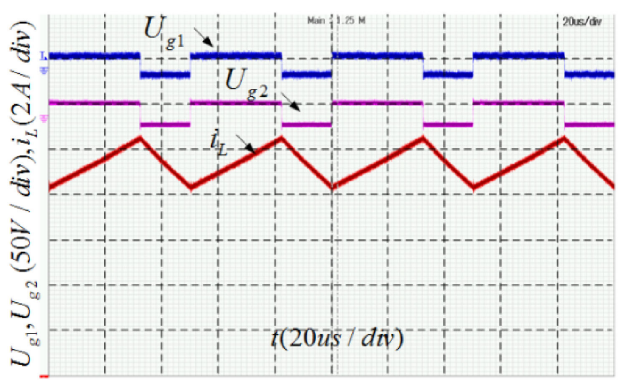

(a) $\mathrm{D}>0.5$

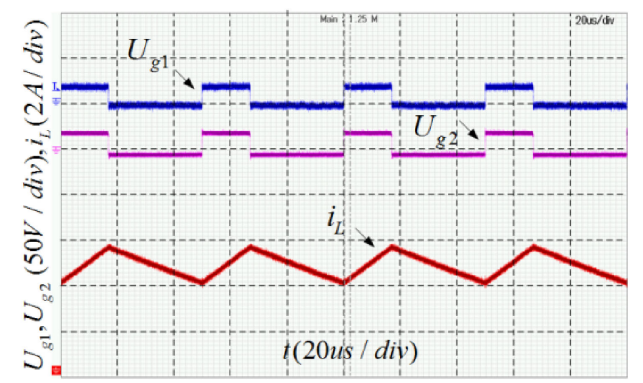

(b) $\mathrm{D}<0.5$

Fig. 5. Experimental waveform of inductor current and duty ratio D without interleaved control 


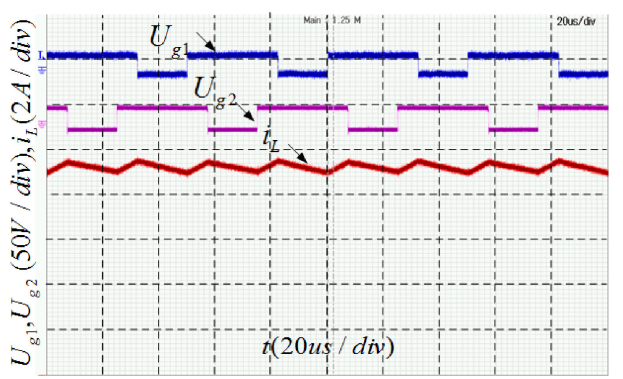

(a) $\mathrm{D}>0.5$

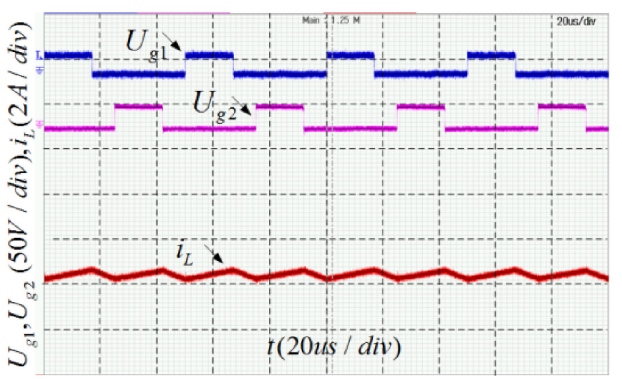

(b) $\mathrm{D}<0.5$

Fig. 6. Experimental waveform of inductor current and duty ratio D with interleaved control

The experimental results of multiloop without and with interleaved control method are shown in Fig. 5 and Fig. 6 separately. The experimental results are consistent with the theoretical analysis, and the proposed MIC method could have lower inductor current ripple. For the same ripple current, the required inductance of filter L has small magnetic components size.

Fig. 7 shows that both the capacitor voltages are balanced after the proposed voltage balancing control loop is applied. It follows that the switch $\mathrm{Q}_{1}$ has larger conducting time than the switch $\mathrm{Q}_{2}$, therefore, the capacitor voltage $\mathrm{U}_{\mathrm{C} 2}$ starts rising and the other capacitor voltage $\mathrm{U}_{\mathrm{C} 1}$ falls. After 100 seconds, the difference between the two capacitor voltages is no more than $10 \mathrm{~V}$.

Fig. 8 shows the experimental results with the MPPT control method. The results show that the PV panel can operate at the maximum power point.

Fig. 9 shows the waveform after the constant current charging loop is applied. It is noted that the charging current keep $11 \mathrm{~A}$ after $3.5 \mathrm{~s}$, and the voltage of battery keeps $360 \mathrm{~V}$.

Curves of measured conversion efficiency between the conventional buck and the proposed three-level buck charger are provided in Fig. 10. As the open circuit voltage exceeds $600 \mathrm{~V}, 1200 \mathrm{~V}$ IGBT (IKW40N120H3) is used for the conventional buck converter. It can be seen that the proposed three-level buck converter has advantage over the conventional two-level buck converter due to using the low voltage devices. The three-level buck converter has more competitive efficiency performance. The maximum efficiency of the proposed converter increases to about $98.7 \%$, and the improvement efficiency at full load is nearly 1.5 percentage.

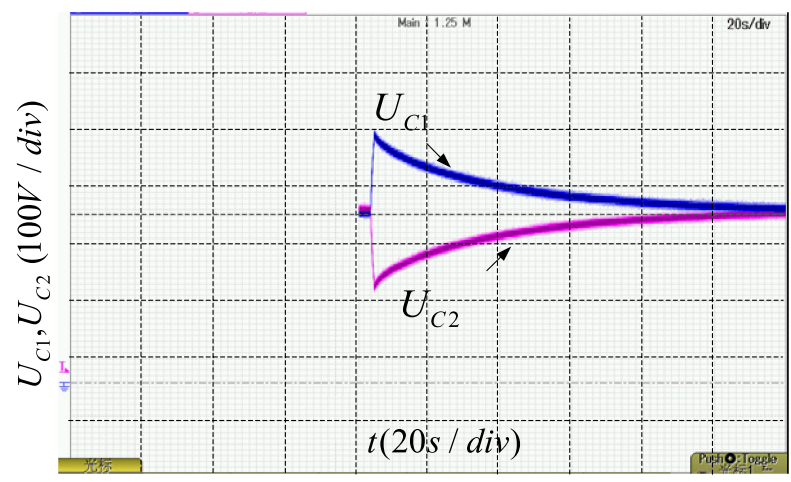




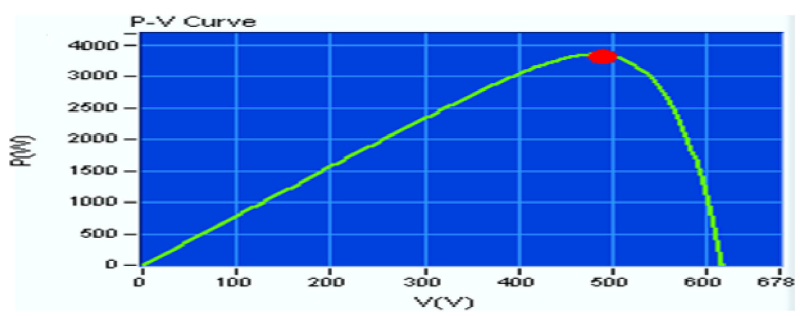

Fig. 8. Experimental results with MPPT control

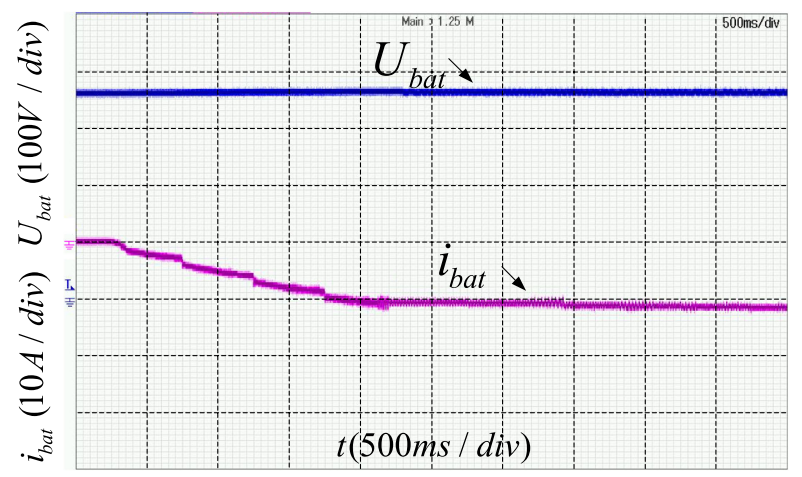

Fig. 9. Experimental waveform after the constant current charging loop is applied

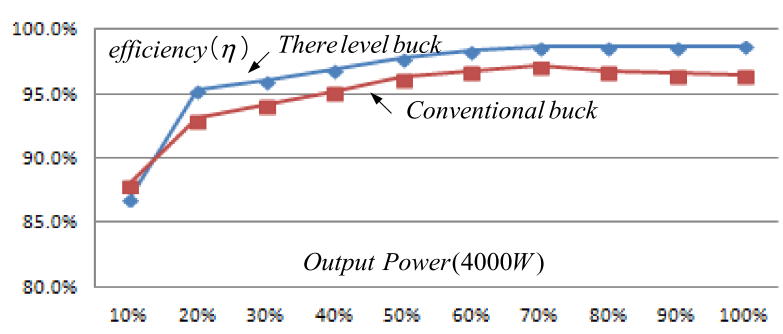

Fig. 10. Comparison of measured Efficiency Curve

From the above analysis, utilization of smaller inductor and low voltage devices yields higher efficiency, lower cost compared with convention buck converter.

\section{Conclusion}

The three-level (TL) buck converter is used for solar battery charger in this paper, and the MIC method for the TL buck converter has been proposed. The capacitor voltage unbalance problem in the TL system is improved by the proposed control algorithm, and lower inductor current ripple, lower switch withstanding voltage could be achieved. Utilization of smaller inductor and low voltage devices yields higher efficiency, higher power density, and lower cost. The control method is implemented in an DSP-based system, and the effectiveness and validity of the proposed method is verified by the experimental results.

\section{Acknowledgments}

This work was supported by Distinguished Young Teacher Project of Education Department of Guangdong Province (YQ2015156). 